\title{
Salinomycin triggers prostate cancer cell apoptosis by inducing oxidative and endoplasmic reticulum stress via suppressing Nrf2 signaling
}

\author{
JIANYONG YU ${ }^{1 *}$, YANG YANG ${ }^{2 *}$, SHAN LI $^{3}$ and PENG MENG ${ }^{3}$ \\ ${ }^{1}$ Department of Urology, Yantai Hospital of Traditional Chinese Medicine; ${ }^{2}$ Department of Urology, Haiyang People's Hospital; \\ ${ }^{3}$ The Fourth Department of Oncology, Yantai Hospital of Traditional Chinese Medicine, Yantai, Shandong 264001, P.R. China
}

Received June 17, 2020; Accepted March 11, 2021

DOI: $10.3892 /$ etm.2021.10378

\begin{abstract}
Salinomycin is a polyether antiprotozoal antibiotic that is widely used as an animal food additive. Some antifungal, antiparasitic, antiviral and anti-inflammatory activities have been reported for salinomycin. Recently, the anti-cancer effect of salinomycin has been demonstrated in breast cancer; however, the underlying mechanism remains unknown. The present study aimed to investigate the functional roles of salinomycin in the progression of prostate cancer cells using the DU145 and PC-3 cell lines. Western blotting and reverse transcription-quantitative polymerase chain reaction were performed to detect the expression of oxidative stress and endoplasmic reticulum stress-related molecules, and flow cytometry was performed to detect the apoptosis rate of DU145 and PC-3 cells after salinomycin treatment. The results demonstrated that salinomycin inhibited the viability and induced the apoptosis of PC-3 and DU145 cells in a dose-dependent manner. Furthermore, salinomycin increased the production of reactive oxygen species (ROS) and 8-hydroxy-2'-deoxyguanosine (8-OH-dG) and the lipid peroxidation. In addition, salinomycin induced the activation of unfolded protein response and endoplasmic reticulum stress in DU145 and PC-3 cells, as indicated by the elevated expression of binding immunoglobulin protein, activating transcription factor 4 , phosphorylated eukaryotic initiation factor $2 \alpha$, phosphorylated protein kinase RNA-like endoplasmic reticulum kinase and C/EBP homologous protein. In addition, salinomycin significantly downregulated the expression of nuclear factor erythroid 2-related factor 2 (Nrf2), heme oxygenase-1, NAD(P)H quinone dehydrogenase 1 and
\end{abstract}

Correspondence to: Dr Peng Meng, The Fourth Department of Oncology, Yantai Hospital of Traditional Chinese Medicine, 39 Xingfu Road, Zhifu, Yantai, Shandong 264001, P.R. China E-mail: yjy20200@163.com

${ }^{*}$ Contributed equally

Key words: salinomycin, prostate cancer, nuclear factor erythroid 2-related factor 2 pathway, apoptosis, endoplasmic reticulum stress glutamate-cysteine ligase catalytic subunit and decreased the activity of the antioxidant enzymes superoxide dismutase, catalase and glutathione peroxidase in PC-3 and DU145 cells. Furthermore, the Nrf2 activator, tert-butylhydroquinone, significantly reversed the therapeutic effects of salinomycin by stimulating the Nrf2 pathway and increasing the activity of antioxidant enzymes. Taken together, these findings demonstrated that salinomycin may trigger apoptosis by inducing oxidative and ER stress in prostate cancer cells via suppressing Nrf2 signaling.

\section{Introduction}

Prostate cancer is characterized by a high morbidity and mortality and is the second most common malignant cancer in men (1). Salinomycin, a monocarboxylic ionophore isolated from Streptomyces albus, is widely used as an animal food additive and has recently been demonstrated to possess anti-cancer effects (2). Salinomycin exhibits antibacterial activity, especially against Gram-positive bacteria and various antibiotic-resistant species of Streptomyces (3). Gupta et al (4) reported that salinomycin selectively kills breast cancer stem cells (CSCs) in tumor xenograft-inoculated mice. Salinomycin activity toward CSCs is 100 -fold higher than the conventional chemotherapeutic drug paclitaxel. However, the efficacy and underlying mechanism of salinomycin in the treatment of prostate cancer remain to be elucidated.

Increased reactive oxygen species (ROS) production has been detected in various cancers (5). Malondialdehyde (MDA) and 8-hydroxy-2'-deoxyguanosine (8-OH-dG) are the end-product of ROS-induced lipid peroxidation and DNA oxidation, respectively, which are commonly used as oxidative stress biomarkers $(6,7)$. Recent studies have suggested that MDA and 8-OH-dG levels in the urine are significantly higher in patients with prostate cancer compared with healthy volunteers $(8,9)$. Recently, the anti-nasopharyngeal carcinoma effect of salinomycin has been widely hypothesized to promote the apoptosis of cancer cells and decrease cancer radioresistance and relapse using a clone formation assay (10). A previous study demonstrated that salinomycin can induce colorectal cancer cell apoptosis by disrupting the osmotic balance (11). Furthermore, treatment of gastric cancer, lung 
cancer and prostate cancer cells with salinomycin in vitro induces autophagy (12), stimulates oxidative stress (13) and has some anti-angiogenic and anti-tumorigenic activities (14), as well as inhibits cancer cell proliferation (15). Furthermore, salinomycin-induced endoplasmic reticulum (ER) stress could improve apoptosis and serve therefore an anti-cancer role in prostate cancer cells (16). However, the exact target and underlying mechanism of salinomycin anti-tumor effect remain unclear.

Nuclear factor erythroid 2-related factor 2 (Nrf2) is a crucial regulator of the cellular antioxidant defense system $(17,18)$. Nrf2 pathway is involved in the regulation of several antioxidative enzymes, including heme oxygenase-1 (HO-1), NAD(P)H quinone oxidoreductase 1 (NQO1) and glutamate-L-cysteine ligase catalytic subunit (GCLc) $(19,20)$. It has been reported that $\mathrm{Nrf} 2$ is overexpressed in squamous cell carcinoma and that it is associated with a poor prognosis for patients, since it stimulates cancer cell survival and proliferation (21). Inhibition of tumor cell proliferation using Nrf2 inhibitors has therefore become a potential anti-cancer therapy strategy. Although a previous study has already shown that salinomycin can inhibit Nrf2 expression and promote the generation of ROS in nasopharyngeal carcinoma (10), the role of salinomycin on the Nrf2 pathway and redox metabolism of prostate cancer cells and its potential molecular mechanism are poorly understood.

The present study aimed to elucidate the role of salinomycin in the treatment of prostate cancer by suppressing Nrf2 antioxidant signaling, promoting oxidative and ER stress and triggering apoptosis in cancer cells. The findings from the present study may help understanding the anti-cancer mechanism of salinomycin.

\section{Materials and methods}

Cell culture. The human prostate cancer cell lines PC-3 and DU145 were purchased from The Cell Bank of Type Culture Collection of The Chinese Academy of Sciences. Cells were cultured in RPMI-1640 medium (cat. no. R0883; Sigma-Aldrich; Merck KGaA) supplemented with 10\% FBS (Welgene, Inc.), $2 \mathrm{mM}$ of L-glutamine, $100 \mathrm{U} / \mathrm{ml}$ of penicillin and $100 \mu \mathrm{g} / \mathrm{ml}$ streptomycin (Welgene, Inc.) and placed at $37^{\circ} \mathrm{C}$ in a humidified incubator containing $5 \% \mathrm{CO}_{2}$.

Cell viability assay. Cells were seeded into 96-well plates at the density of 5,000 cells/well. After $24 \mathrm{~h}$ incubation, cells were treated with 2 and $5 \mu \mathrm{M}$ salinomycin, $10 \mu \mathrm{M}$ tBHQ (Nrf2 activator) or $10 \mu \mathrm{M}$ ML385 (Nrf2 inhibitor) for $72 \mathrm{~h}$ (22-24). Salinomycin (Sigma-Aldrich; Merck KGaA) was dissolved in DMSO to create the stock solution. Cell viability was assessed using the Cell Titer Glo Assay (cat. no. G7570; Promega Corporation) according to the manufacturer's protocol.

Cell apoptosis analysis. Apoptosis was assessed using a Annexin V-FITC apoptosis detection kit (BD Biosciences). Briefly, PC-3 and DU145 cells were cultured in 6-well plates at a density of $5 \times 10^{4} /$ well. After treatment with 2 and $5 \mu \mathrm{M}$ salinomycin for $72 \mathrm{~h}$, cells were harvested, mixed in $100 \mu \mathrm{l}$ binding buffer and stained with $10 \mu \mathrm{l}$ Annexin-V/propidium iodide (PI) at room temperature for $15 \mathrm{~min}$. The stained cells were analyzed by flow cytometry (FACSCalibur; Becton, Dickinson and Company) and the apoptotic rate was calculated using Cell Quest Pro software (version 5.1) on Mac ${ }^{\circledR} \mathrm{OS} 9$ (Becton, Dickinson and Company).

Detection of ROS. The intracellular ROS level was evaluated using the ROS assay kit (cat. no. MAK145; Sigma-Aldrich; Merck $\mathrm{KGaA}$ ) according to the manufacturer's instructions. Briefly, the PC-3 and DU145 cells were plated in a 96-well plate $\left(5 \times 10^{4}\right.$ cells/well). Following treatment with 2 and $5 \mu \mathrm{M}$ salinomycin for $72 \mathrm{~h}$, cells were washed with Hanks balanced salt solution (HBSS) and incubated with $500 \mu \mathrm{M}$ of the luminol derivative L-012 in $\mathrm{HBSS}$ at $37^{\circ} \mathrm{C}$ for $15 \mathrm{~min}$. ROS-induced chemiluminescence was determined every $10 \mathrm{~min}$ for a total of 60 min using a Microplate Luminometer (Tropix TR717; Applied Biosystems; Thermo Fisher Scientific, Inc.).

Detection of MDA. MDA was quantified as thiobarbituric acid reactive substances (TBARS) as previously described by Xiong et al (25). Briefly, $5 \times 10^{6}$ cells were sonicated in $200 \mu \mathrm{l}$ ice-cold PBS and $100 \mu \mathrm{l}$ cell lysate was placed into a $1.5 \mathrm{ml}$ micro-centrifuge tube. After adding $200 \mu \mathrm{l}$ ice-cold $10 \%$ trichloroacetic acid (TCA) to the cell lysate, the samples were incubated for $5 \mathrm{~min}$ on ice. After centrifugation at $10,000 \times \mathrm{g}$ for $15 \mathrm{~min}$ at $4^{\circ} \mathrm{C}$, the supernatant was collected and mixed with $1 \mathrm{ml} \mathrm{10 \%} \mathrm{TCA} \mathrm{and} 1 \mathrm{ml} \mathrm{0.67 \%} \mathrm{thiobarbituric}$ acid. The mixture was subsequently heated in a boiling water bath for $30 \mathrm{~min}$. TBARS were determined by reading the absorbance at $532 \mathrm{~nm}$.

Detection of $8-O H-d G$. Cell nuclear DNA was isolated using the sodium iodide method. Briefly, total DNA was isolated from cells with DNAzol reagent (Thermo Fisher Scientific, Inc.). UV spectrophotometry was used for the quantification of the isolated DNA (26). 8-OH-dG was measured using OxiSelect ${ }^{\mathrm{TM}}$ Oxidative DNA Damage ELISA kit (cat. no. STA-320; Cell Biolabs, Inc.) according to the manufacturer's protocol (26).

Activity of antioxidant enzymes. The activity of the antioxidant enzymes catalase (CAT), glutathione peroxidase (GSH-Px) and superoxide dismutase (SOD) was determined by spectrophotometrical methods (27). GSH-Px activity was detected using the DTNB method (28) (cat. no. A005-1-2), CAT activity was measured using the ammonium molybdate method (29) (cat. no. A007-1-1) and SOD activity was measured using the xanthine-oxidase method (30) (cat. no. A001-3-2; all from Nanjing Jiancheng Bioengineering Institute).

Western blot analysis. Cells were lysed in RIPA buffer (cat. no. R0010) with PMSF (cat. no. P0100; both from Beijing Solarbio Science \& Technology Co., Ltd.) for $30 \mathrm{~min}$ on ice. Protein concentration was determined using a Bradford Protein Assay kit (cat. no. PC0010; Beijing Solarbio Science $\&$ Technology Co., Ltd.). A total of $30 \mu \mathrm{g}$ protein/lane were separated by $10 \%$ SDS-PAGE and transferred onto PVDF membranes. Membranes were blocked with $5 \%$ skimmed milk powder at $4^{\circ} \mathrm{C}$ overnight and incubated with primary antibodies (1:1,000; Cell Signaling Technology, Inc.) against binding immunoglobulin protein (Bip; cat. no. 3117 ), eukaryotic initiation factor $2 \alpha$ (eIF2 $\alpha$; cat. no. 5324), 
phosphorylated (p)-eIF2 $\alpha$ (cat. no. 5199), protein kinase RNA-like endoplasmic reticulum kinase (PERK; cat. no. 5683), p-PERK (cat. no. 3179), activating transcription factor 4 (ATF4; cat. no. 11815), C/EBP homologous protein (CHOP; cat. no. 2895), Nrf2 (cat. no. 12721), GCLc (cat. no. 19689), HO-1 (cat. no. 86806), NQO1 (cat. no. 3187) and GAPDH (cat. no. 5174) overnight at $4^{\circ} \mathrm{C}$. Membranes were then incubated with HRP-conjugated goat anti-mouse $\operatorname{IgG}(\mathrm{H}+\mathrm{L})$ secondary antibody (1:3,000; cat. no. SE131) or HRP-conjugated goat anti-rabbit $\operatorname{IgG}(\mathrm{H}+\mathrm{L})$ secondary antibody $(1: 3,000$; cat. no. SE134; both from Beijing Solarbio Science \& Technology Co., Ltd.) at room temperature for $1 \mathrm{~h}$, followed by washing three times with TBS-Tween $(0.1 \%$ Tween-20) for $10 \mathrm{~min}$ each. Enhanced chemiluminescence reagent (Thermo Fisher Scientific, Inc.) was used to detect the signal on the membrane. The data were analyzed using Tanon-410 automatic gel imaging system (Shanghai Tianneng Corporation, China) and normalized to expression of the internal control (GAPDH).

Reverse transcription-quantitative polymerase chain reaction $(R T-q P C R)$. The expression level of CHOP was determined using RT-qPCR. mRNA was isolated from PC-3 and DU145 cells using TRI reagent following the manufacturer's instructions (cat. no. T9424; Sigma-Aldrich; Merck KGaA). cDNA synthesis was performed using the GoScript Reverse Transcription System (Promega Corporation) following the manufacturer's instructions. The reaction mixture contained $6.25 \mu 1$ 2X GoTaq qPCR Master Mix (Promega Corporation), $1 \mu \mathrm{l}$ cDNA, $0.25 \mu \mathrm{l}$ upstream PCR primers and $0.25 \mu \mathrm{l}$ downstream PCR primers. Nuclease-free water was added to a final volume of $12.5 \mu \mathrm{l}$. Each reaction was run in triplicate. The qPCR reaction conditions were subjected to an initial predenaturation step at $95^{\circ} \mathrm{C}$ for $3 \mathrm{~min}$, followed by 39 cycles of $95^{\circ} \mathrm{C}$ for $20 \mathrm{sec}$ and $60^{\circ} \mathrm{C}$ for $30 \mathrm{sec}$. The relative expression levels were normalized to endogenous control $\beta$-actin and were expressed as $2^{-\Delta \Delta C q}(31)$. The sequences of the primers used were as follows: CHOP, forward 5'-CTTCCATGTAGCGGA GTCCT-3'; reverse 5'-GTGAGAGCCAGTCTCCCTTT-3'; and $\beta$-actin, forward 5'-CACCACACCTTCTACAATGAG-3' and reverse 5'-TACGACCAGAGGCATACAG-3'.

Statistical analysis. Statistical analyses were performed using SPSS software (version 22.0; IBM Corp.). Data were presented as the means \pm standard deviation of three independent experiments. Differences were compared using ANOVA followed by Dunnett's or Tukey's post hoc tests. $\mathrm{P}<0.05$ was considered to indicate a statistically significant difference.

\section{Results}

Effects of salinomycin on prostate cancer cell proliferation and apoptosis. The effects of salinomycin on the proliferation and apoptosis of PC-3 and DU145 cells were determined for different concentrations $(0,2,5,10,20$ and $50 \mu \mathrm{M})$. As seen in Fig. 1A and B, the proliferation of PC-3 and DU145 cells was significantly decreased following treatment with salinomycin (2-50 $\mu \mathrm{M})$. In addition, salinomycin treatment significantly increased the apoptosis of PC-3 and DU145 cells in a dose-dependent manner (Fig. 1C-E). These data indicated that salinomycin significantly inhibited the proliferation and induced the apoptosis of prostate cancer cells.

Salinomycin treatment increases oxidative stress in prostate cancer cells. To determine the impact of salinomycin on prostate cancer cell oxidative stress, the level of ROS was determined in PC-3 and DU145 cells following treatment with 2 and $5 \mu \mathrm{M}$ salinomycin for $72 \mathrm{~h}$. The results demonstrated that salinomycin significantly increased the production of ROS in a dose-dependent manner in PC-3 and DU145 cells (Fig. 2A and B). Furthermore, a significantly increase in MDA levels in PC-3 and DU145 cells following salinomycin treatment was observed (Fig. 2C and D). In addition, the levels of 8-OH-dG, which is a marker of oxidative stress-induced DNA damage, were determined. As presented in Fig. 2E and F, 8-OH-dG levels were significantly increased in PC-3 and DU145 cells after salinomycin treatment. These data indicated that salinomycin treatment promoted the production of ROS and caused lipid peroxidation of polyunsaturated fatty acid and DNA damage.

Salinomycin increased ER stress in prostate cancer cells. To determine whether salinomycin could induce ER stress in PC-3 and DU145 cells, the expression of ER stress-related proteins was determined by western blotting (Fig. 3A). The results demonstrated that salinomycin treatment caused the significant upregulation of the ER stress biomarkers Bip (Fig. 3B), ATF4 (Fig. 3E) and CHOP (Fig. 3F) in both PC-3 and DU145 cells. Furthermore, the expression of p-eIF2 $\alpha$ (Fig. 3C) and p-PERK (Fig. 3D) was significantly increased in both PC-3 and DU145 cells following treatment with salinomycin. These findings indicated that salinomycin could increase the expression of ER stress regulatory proteins in prostate cancer cells.

Salinomycin inhibits the activation of Nrf2 signaling in prostate cancer cells. Whether salinomycin could regulate the activation of Nrf2 pathway, which is the essential signaling transduction pathway involved in anti-oxidative response, was further investigated. As shown in Fig. 4A and B, salinomycin treatment significantly decreased Nrf2 expression in both PC-3 and DU145 cells. In addition, the expression of Nrf2 downstream target proteins GCLc, HO-1 and NQO1, was significantly decreased in salinomycin treated groups compared with control group (Fig. 4A and C-E).

Furthermore, cell treatment with salinomycin and the Nrf2 activator tert-butylhydroquinone (tBHQ) significantly increased the expression of Nrf2 in both PC-3 and DU145 cells compared with treatment with salinomycin alone (Fig. 5A). Conversely, cell treatment with salinomycin and the Nrf2 inhibitor ML385 significantly decreased the expression of Nrf2 in both PC-3 and DU145 cells compared with treatment with salinomycin alone (Fig. 5A). These data indicated that salinomycin treatment could inhibit the activity of Nrf2 signaling in prostate cancer cells.

Salinomycin decreases the activity of antioxidant enzymes and increases the apoptosis of prostate cancer cells via inhibiting Nrf 2 pathway. To determine the relationship between salinomycin-induced Nrf2 signaling inhibition and the change in antioxidant enzyme activity in prostate cancer 

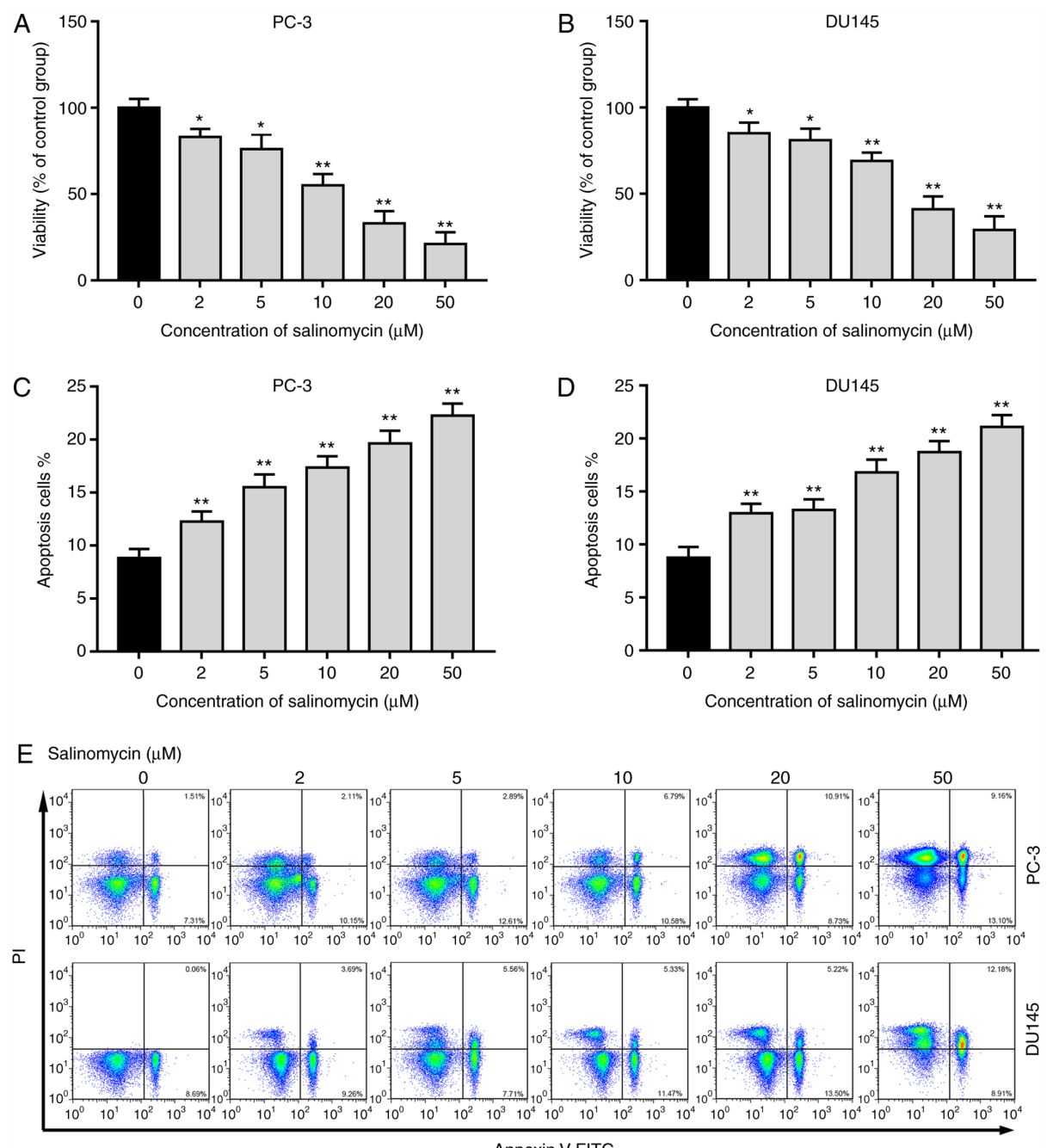

Figure 1. Effects of salinomycin on the proliferation and apoptosis of prostate cancer cells. Prostate cancer PC-3 and DU145 cells were treated with various concentrations of salinomycin for $72 \mathrm{~h}$. Effect of salinomycin on the proliferation of (A) PC-3 and (B) DU145 cells was determined using cell proliferation assay. (C-E) Effect of salinomycin on the apoptosis of PC-3 and DU145 cells was determined using Annexin V-FITC apoptosis detection kit. Data were presented as the means \pm standard deviation. ${ }^{*} \mathrm{P}<0.05$ and ${ }^{* * *} \mathrm{P}<0.01$ vs control.

A
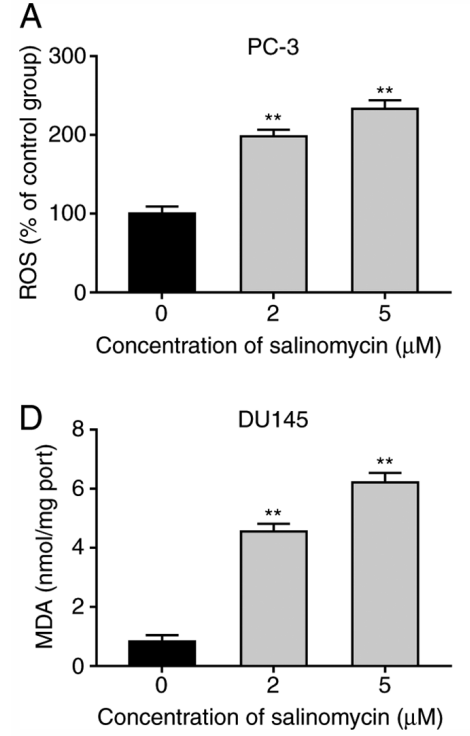

B
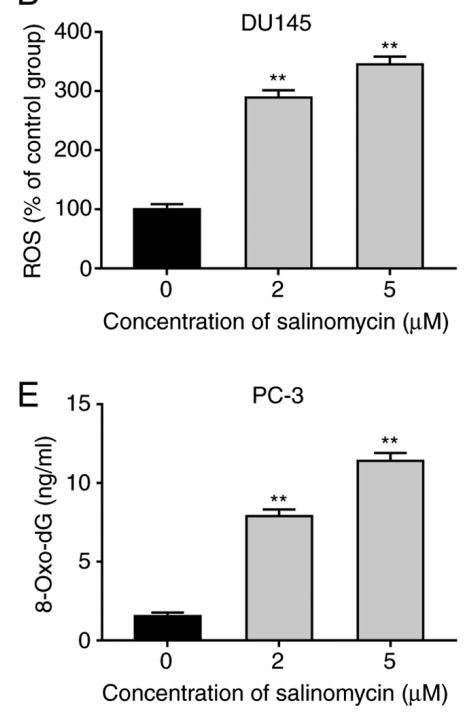

C
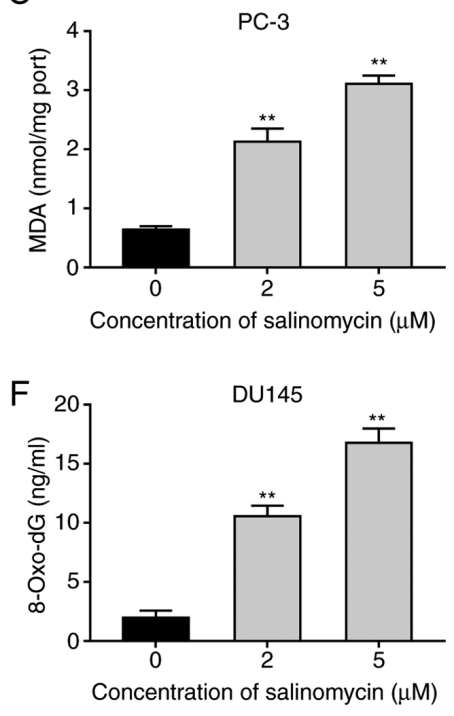

Figure 2. Salinomycin promotes prostate cancer cell oxidative stress. Prostate cancer PC-3 and DU145 cells were treated with 2 and $5 \mu \mathrm{M}$ salinomycin for $72 \mathrm{~h}$. Effect of salinomycin on the ROS levels of (A) PC-3 and (B) DU145 cells. Effect of salinomycin on the MDA levels of (C) PC-3 and (D) DU145 cells. Effect of salinomycin on the 8-OH-dG levels of (E) PC-3 and (F) DU145 cells. Data were presented as the means \pm standard deviation. ${ }^{* *} \mathrm{P}<0.01$ vs. control. ROS, reactive oxygen species; MDA, malondialdehyde; 8-OH-dG, 8-hydroxy-2'-deoxyguanosine. 
A

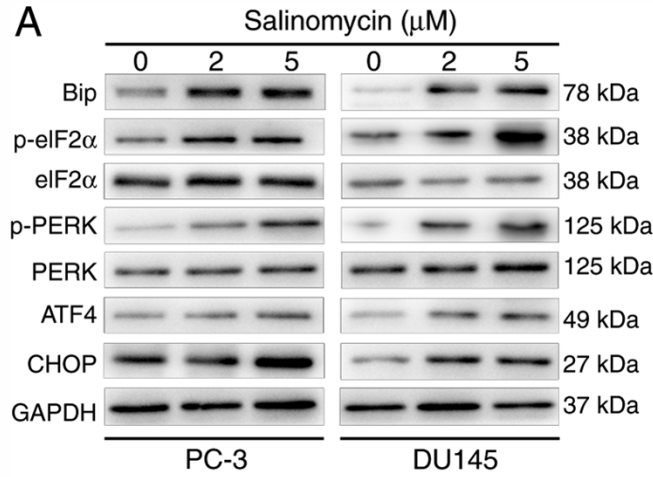

$\mathrm{B}$

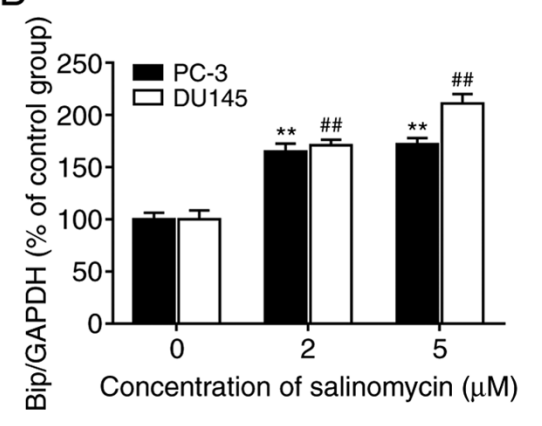

E⿳亠्厂े

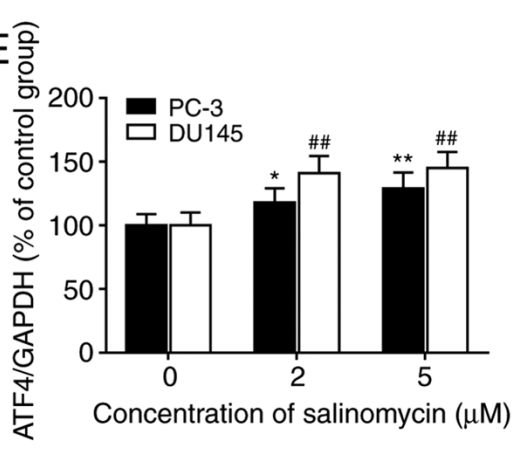

C

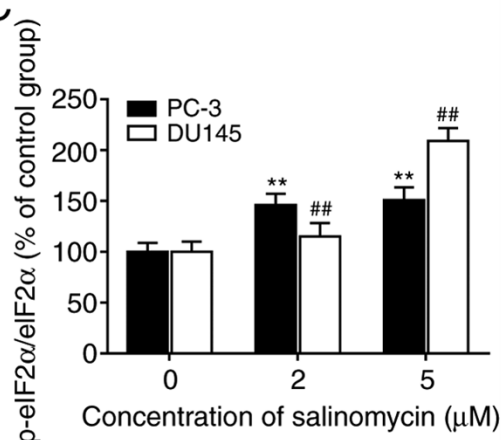

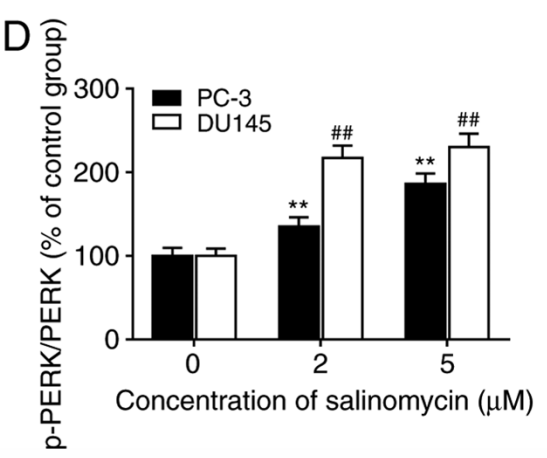

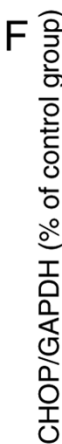

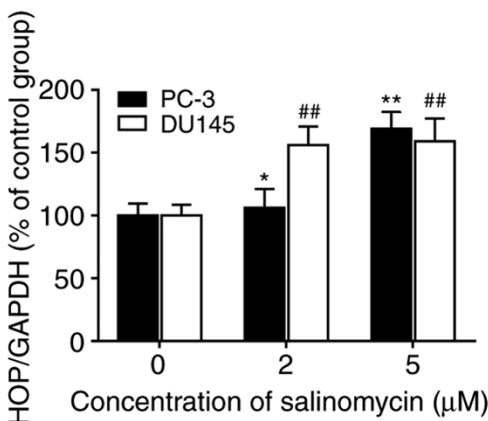

Figure 3. Salinomycin promotes prostate cancer cell ER stress. Prostate cancer cells PC-3 and DU145 were treated with 2 and $5 \mu \mathrm{M}$ salinomycin for $72 \mathrm{~h}$. (A) Effect of salinomycin on ER stress biomarker was assessed by western. Bip, p-eIF2 $\alpha$, eIF2 $\alpha$, p-PERK, PERK, ATF4, CHOP and GAPDH protein electrophoresis images. (B-F) Relative quantification of protein expression from bands in (A). Data were presented as the means \pm standard deviation. ${ }^{*} \mathrm{P}<0.05$ and ${ }^{* *} \mathrm{P}<0.01$ vs. PC-3 cells control. ${ }^{\# \#} \mathrm{P}<0.01$ vs. DU145 cells control. ER, endoplasmic reticulum; Bip, binding immunoglobulin protein; eIF2 $\alpha$, eukaryotic initiation factor $2 \alpha$; p, phosphorylated; PERK, protein kinase RNA-like endoplasmic reticulum kinase; ATF4, activating transcription factor 4; CHOP, C/EBP homologous protein.
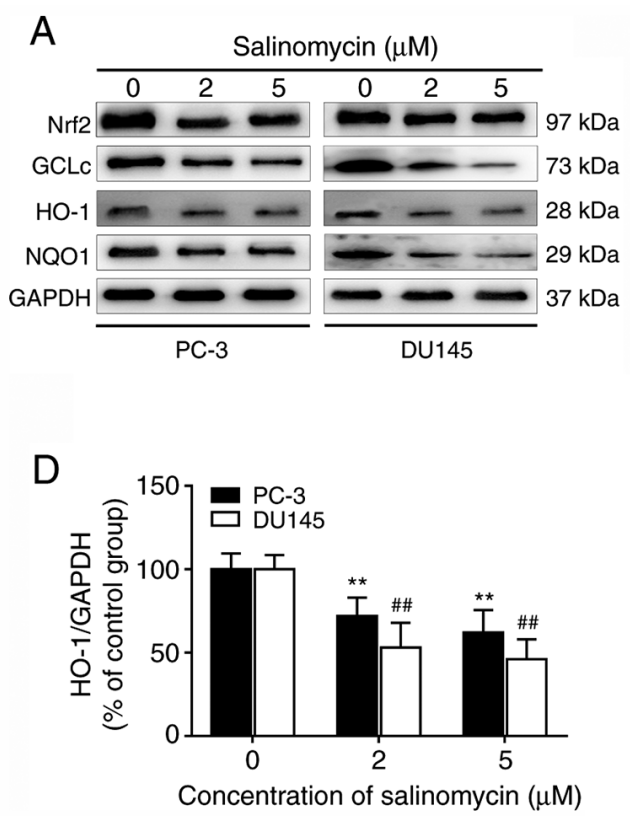

$\mathrm{B} \cong$
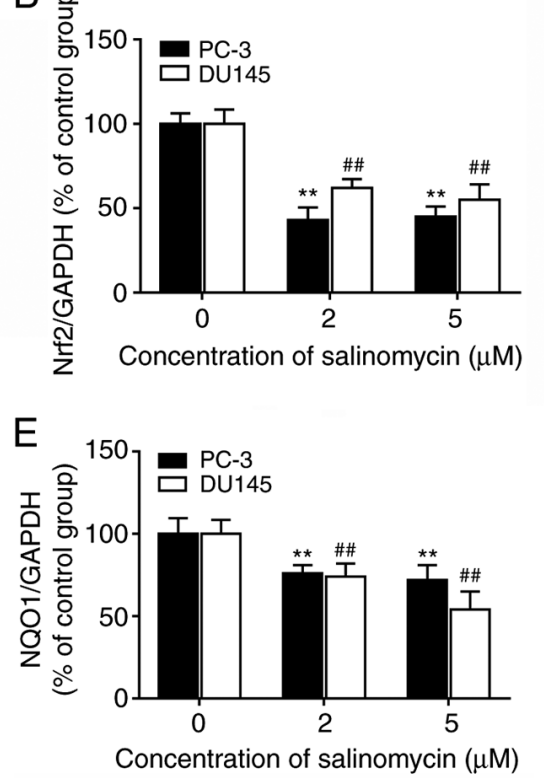

C

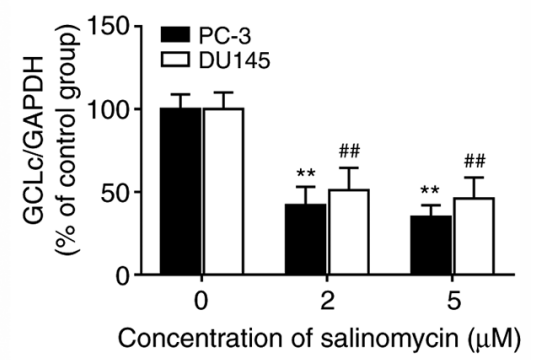

Concentration of salinomycin $(\mu \mathrm{M})$

Figure 4. Salinomycin inhibits Nrf2 pathway in prostate cancer cells. Prostate cancer cells PC-3 and DU145 were treated with 2 and $5 \mu$ M salinomycin for 72 h. (A) Effect of salinomycin on the expression of Nrf2 and downstream proteins was assessed by western blotting. Nrf2, GCLc, HO-1, NQO1 and GAPDH protein electrophoresis images. (B-E) Relative quantification of protein expression from bands in (A). Data were presented as the means \pm standard deviation. ${ }^{* *} \mathrm{P}<0.01$ vs. PC-3 cells control. ${ }^{\# \#} \mathrm{P}<0.01$ vs. DU145 cells control. GCLc, glutamate-L-cysteine ligase catalytic subunit; Nrf2, nuclear factor erythroid 2-related factor 2; HO-1, heme oxygenase-1; NQO1, NAD(P)H quinone dehydrogenase 1.

cells, the activities of SOD, CAT and GSH-Px were determined following treatment of PC-3 and DU145 cells with
$5 \mu \mathrm{M}$ salinomycin, $10 \mu \mathrm{M}$ tBHQ, $10 \mu \mathrm{M}$ ML385 or DMSO vehicle for $72 \mathrm{~h}$. As presented in Fig. 5B-D, the activities of 

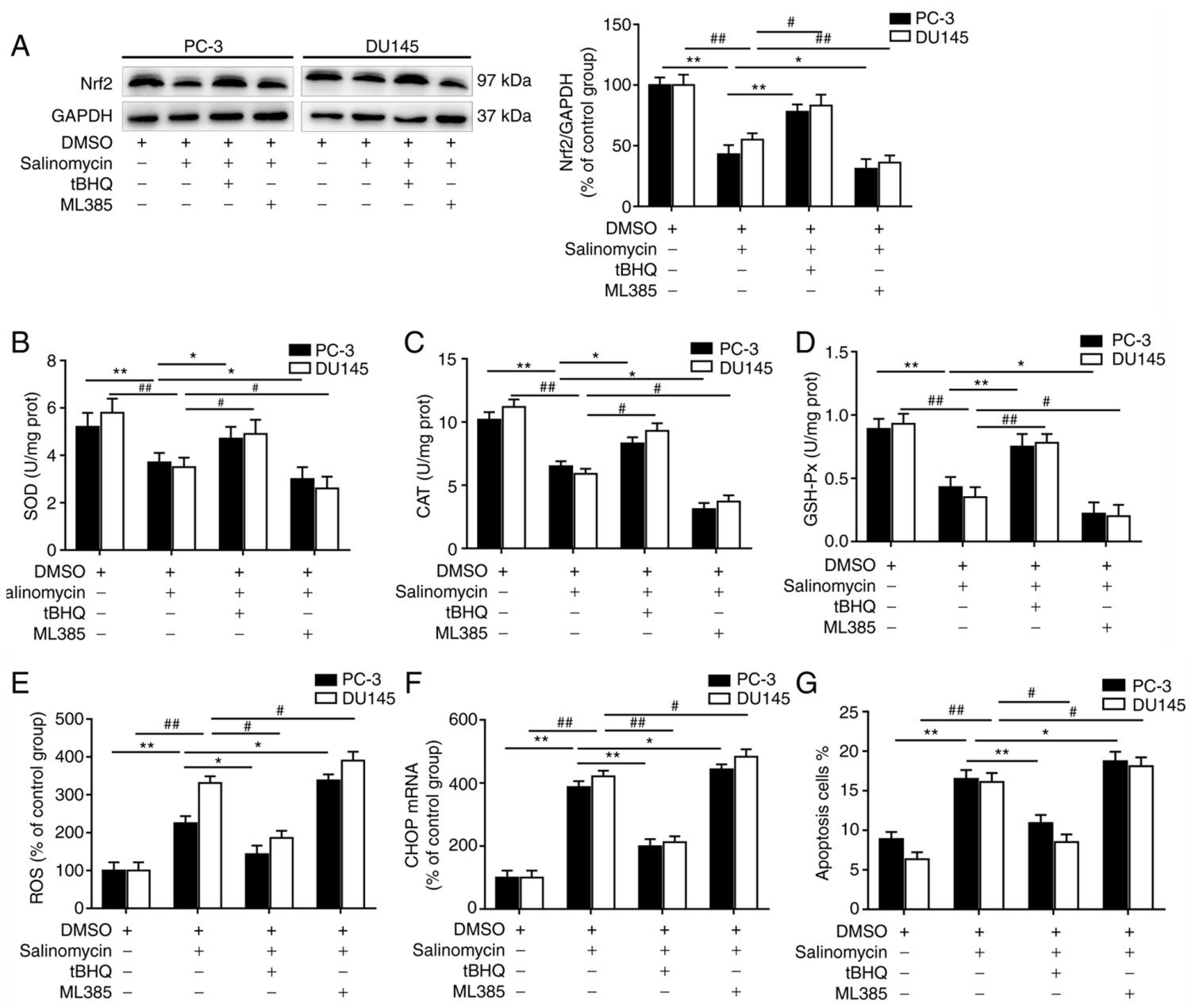

$\mathrm{H}$

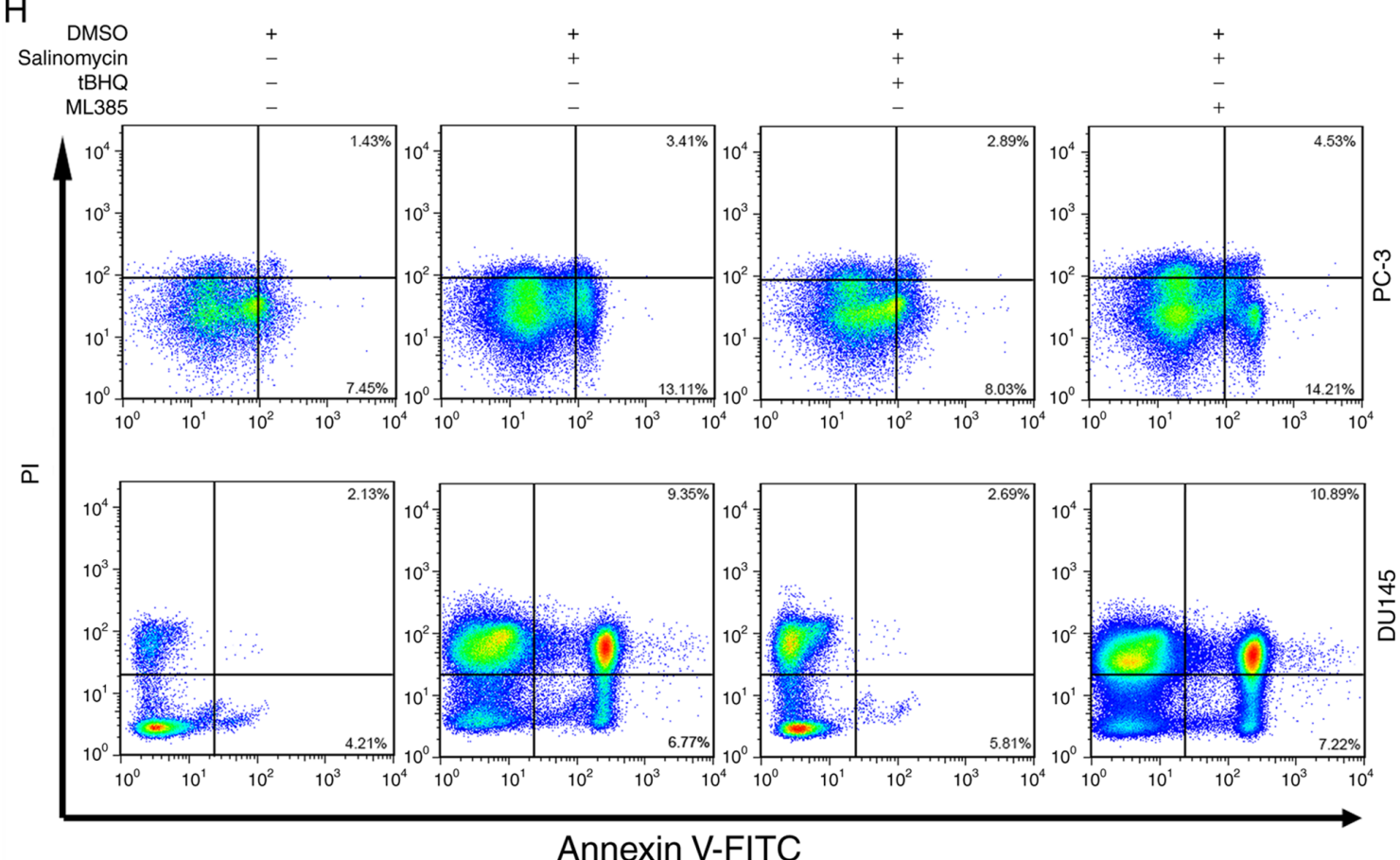

Figure 5. Salinomycin decreases the activity of antioxidant enzymes and increases the apoptosis via inhibiting Nrf2 pathway in prostate cancer cells. Prostate cancer cells PC-3 and DU145 were treated with $5 \mu \mathrm{M}$ salinomycin, $10 \mu \mathrm{M}$ tBHQ (Nrf2 activator), $10 \mu \mathrm{M}$ ML385 (Nrf2 inhibitor) or DMSO vehicle for 72 h. (A) Expression of Nrf2 was assessed by western blotting. Antioxidant enzyme activity of (B) SOD, (C) CAT and (D) GSH-Px and (E) intracellular ROS levels. (F) Expression of CHOP was detected by reverse transcription-quantitative polymerase chain reaction. (G and $\mathrm{H}$ ) Apoptosis was detected using Annexin V-FITC apoptosis detection kit. Data were presented as the means \pm standard deviation. ${ }^{*} \mathrm{P}<0.05$ and ${ }^{* *} \mathrm{P}<0.01$ vs. $\mathrm{PC}-3$ control. ${ }^{\#} \mathrm{P}<0.05$ and ${ }^{\# \#} \mathrm{P}<0.01$ vs. DU145 control. tBHQ, tert-butylhydroquinone; SOD, superoxide dismutase; ROS, reactive oxygen species; CAT, catalase; GSH-Px, glutathione peroxidase; CHOP, C/EBP homologous protein. 
SOD, CAT and GSH-Px were significantly decreased after salinomycin treatment. Furthermore, tBHQ treatment signifcantly increased the activities of SOD, CAT and GSH-Px in the two prostate cancer cell lines compared with treatment with salinomycin alone. Conversely, ML385 treatment significantly decreased the activities of SOD, CAT and GSH-Px in both PC-3 and DU145 cells compared with treatment with salinomycin alone.

The effects of Nrf2 inhibitor and activator on salinomycin-induced oxidative and ER stress in prostate cancer cells were further investigated. As presented in Fig. 5E and F, ROS levels and CHOP expression were significantly decreased folowing tBHQ treatment compared with treatment with salinomycin alone. Furthermore, tBHQ treatment signifcantly decreased the apoptosis in both PC-3 and DU145 cells compared with treatment with salinomycin alone (Fig. 5G). Conversely, ML385 treatment significantly elevated ROS level, CHOP expression and apoptosis in both prostate cancer cell lines compared with treatment with salinomycin alone (Fig. 5E-H).

\section{Discussion}

Prostate cancer is a commonly diagnosed cancer in men. The present study demonstrated a potential important role of salinomycin in mediating the apoptosis of prostate cancer cells by increasing oxidative and ER stress through the inhibition of Nrf2 antioxidant signaling.

Salinomycin is a monocarboxylic ionophore isolated from Streptomyces albus (2). Salinomycin ability to kill cancer stem cells and therapy-resistant cancer cells may allow this compound to be considered as a potential novel chemotherapeutic drug (32). The present study demonstrated that salinomycin significantly inhibited the proliferation and induced the apoptosis of PC-3 and DU145 cells in a dose-dependent manner. It was previously reported that cancer chemopreventive agents cancer induce apoptosis partly via ROS generation and disruption of the redox homeostasis (33). The results from the present study demonstrated that salinomycin could promote ROS accumulation, lipid peroxidation of polyunsaturated fatty acids and DNA damage. These findings were consistent with results from a previous study demonstrating that salinomycin inhibits prostate cancer cell proliferation and migration by reducing the expression of key prostate cancer oncogenes, inducing oxidative stress, decreasing the antioxidative capacity and diminishing cancer stem cell fraction (13).

The ER is an essential intracellular organelle that is crucial for multiple cellular functions, including protein folding and maturation and maintenance of cellular homeostasis. ER stress is activated by a variety of factors and triggers the unfolded protein response (UPR), which restores homeostasis or activates cell death (34). Previous studies have reported that UPR signaling pathways are closely related to autophagy, apoptosis, inflammatory response and oxidative stress in cancer cells (35-37). The PERK/ATF4/CHOP pathway plays an important role in modulating anti- and pro-apoptotic proteins, such as B-cell lymphoma-2 (Bcl-2) family members that control mitochondrial apoptosis (38). Similarly, the present study demonstrated that the expression of UPR proteins, including
Bip, ATF4, p-PERK, p-eIF2 $\alpha$ and CHOP, was significantly increased in PC-3 and DU145 cells treated with salinomycin. Previous studies have reported that ROS activate PERK signal transduction, which induces apoptosis via ER stress in choriocarcinoma cells (39). Furthermore, ROS may play a role in cell death via the p-eIF2 $\alpha / \mathrm{ATF} 4 / \mathrm{CHOP}$ axis (40). Taken together, these results indicate that salinomycin may initiate prostate cancer cell apoptosis by promoting ROS production and ER stress.

Nrf2 is a key regulator of the antioxidant system $(41,42)$. Recent studies have demonstrated that regulation of the Nrf2 signaling pathway is involved in the pathogenesis and treatment of various cancers (43-45). In the present study, salinomycin effectively downregulated the expression of Nrf2, HO-1, NQO1 and GCLc in prostate cancer cell lines. Cell treatment with the Nrf2 activator tBHQ significantly reversed the therapeutic effects of salinomycin by promoting the expression of the Nrf2 pathway and antioxidant enzyme activities. In addition, cell treatment with the Nrf2 inhibitor ML385 promoted the therapeutic effects of salinomycin. These results indicated that salinomycin may promote some anti-cancer effects by inhibiting the Nrf2 pathway in prostate cancer cells. These results were in agreement with previous results demonstrating that salinomycin overcomes radioresistance in nasopharyngeal carcinoma cells by inhibiting Nrf2 levels and promoting ROS production (10).

To test our hypothesis, we explored the influence of salinomycin on antioxidant enzyme activity in prostate cancer cells. The results demonstrated that salinomycin treatment significantly downregulated the activities of CAT, GSH-Px and SOD. Furthermore, Nrf2 activator tBHQ treatment significantly increased the activities of antioxidant enzymes and inhibited the apoptosis promoting effect of salinomycin on prostate cancer cells. Conversely, the Nrf2 inhibitor ML385 promoted apoptosis of prostate cancer cells and enhanced the anti-cancer effect of salinomycin by reducing the antioxidant capacity and increasing oxidative stress and ER stress. These results suggested that salinomycin treatment may reduce the activity of antioxidant enzymes by inhibiting the Nrf2 pathway in prostate cancer cells that become more susceptible to oxidative damage. These results were in line with the upregulated ROS levels, CHOP expression and apoptosis in prostate cancer cells.

In conclusion, to the best of our knowledge, the present study demonstrated for the first time that salinomycin, which is a potent antitumor agent, exhibited some anti-cancer activities on human prostate cancer cells by inducing ROS and ER stress-dependent apoptosis via suppressing Nrf2 antioxidant signaling. These findings elucidated the anti-cancer effects and underlying mechanism of salinomycin and may help the development of novel therapeutic strategies against prostate cancer.

\section{Acknowledgements}

Not applicable.

\section{Funding}

No funding was received. 


\section{Availability of data and materials}

The datasets used and/or analyzed during the current study are available from the corresponding author on reasonable request.

\section{Authors' contributions}

PM and JY conceived and designed the experiments and wrote the manuscript. SL and YY performed the experiments and were responsible for data analysis and interpretation. PM and JY confirmed the authenticity of all the raw data. All authors have read and approved the final manuscript.

\section{Ethics approval and consent to participate}

Not applicable.

\section{Patient consent for publication}

Not applicable.

\section{Competing interests}

The authors declare that they have no competing interests.

\section{References}

1. Siegel R, Naishadham D and Jemal A: Cancer statistics, 2013. CA Cancer J Clin 63: 11-30, 2013.

2. Naujokat C, Fuchs D and Opelz G: Salinomycin in cancer: A new mission for an old agent. Mol Med Rep 3: 555-559, 2010.

3. Huczyński A, Janczak J, Antoszczak M, Wietrzyk J, Maj E and Brzezinski B: Antiproliferative activity of salinomycin and its derivatives. Bioorg Med Chem Lett 22: 7146-7150, 2012.

4. Gupta PB, Onder TT, Jiang G, Tao K, Kuperwasser C, Weinberg RA and Lander ES: Identification of selective inhibitors of cancer stem cells by high-throughput screening. Cell 138: 645-659, 2009.

5. Moloney JN and Cotter TG: ROS signalling in the biology of cancer. Semin Cell Dev Biol 80: 50-64, 2018.

6. Mizoue T, Tokunaga S, Kasai H, Kawai K, Sato M and Kubo T: Body mass index and oxidative DNA damage: A longitudinal study. Cancer Sci 98: 1254-1258, 2007.

7. Xiao MH, Xia JY, Wang ZL, Hu WX, Fan YL, Jia DY, Li J, Jing PW, Wang L and Wang YP: Ginsenoside Rg1 attenuates liver injury induced by D-galactose in mice. Exp Ther Med 16: 4100-4106, 2018.

8. Chang WH, Lee CC, Yen YH and Chen HL: Oxidative damage in patients with benign prostatic hyperplasia and prostate cancer co-exposed to phthalates and to trace elements. Environ Int 121: 1179-1184, 2018.

9. Arif M, Rashid A, Majeed A, Qaiser F and Razak S: Evaluation of correlation between expression of P53 and Malondialdehyde levels in prostate cancer patients. J Pak Med Assoc 68: 1373-1377, 2018.

10. Zhang G, Wang W, Yao C, Ren J,Zhang S and Han M: Salinomycin overcomes radioresistance in nasopharyngeal carcinoma cells by inhibiting Nrf2 level and promoting ROS generation. Biomed Pharmacother 91: 147-154, 2017.

11. Zhou J, Li P, Xue X, He S, Kuang Y, Zhao H, Chen S, Zhi Q and Guo X: Salinomycin induces apoptosis in cisplatin-resistant colorectal cancer cells by accumulation of reactive oxygen species. Toxicol Lett 222: 139-145, 2013.

12. Li T, Su L, Zhong N, Hao X, Zhong D, Singhal S and Liu X: Salinomycin induces cell death with autophagy through activation of endoplasmic reticulum stress in human cancer cells. Autophagy 9: 1057-1068, 2013.

13. Ketola K, Hilvo M, Hyötyläinen T, Vuoristo A, Ruskeepää AL, Orešič M, Kallioniemi $\mathrm{O}$ and Iljin K: Salinomycin inhibits prostate cancer growth and migration via induction of oxidative stress. Br J Cancer 106: 99-106, 2012.
14. Li T, Liu X, Shen Q, Yang W, Huo Z, Liu Q, Jiao H and Chen J: Salinomycin exerts anti-angiogenic and anti-tumorigenic activities by inhibiting vascular endothelial growth factor receptor 2-mediated angiogenesis. Oncotarget 7: 26580-26592, 2016.

15. Wu D, Zhang Y, Huang J, Fan Z, Shi F and Wang S: Salinomycin inhibits proliferation and induces apoptosis of human nasopharyngeal carcinoma cell in vitro and suppresses tumor growth in vivo. Biochem Biophys Res Commun 443: 712-717, 2014.

16. Zhang Y, Li F, Liu L, Jiang H, Hu H, Du X, Ge X, Cao J and Wang Y: Salinomycin triggers endoplasmic reticulum stress through ATP2A3 upregulation in PC-3 cells. BMC Cancer 19: 381, 2019.

17. Menegon S, Columbano A and Giordano S: The dual roles of Nrf2 in cancer. Trends Mol Med 22: 578-593, 2016.

18. Lau A, Villeneuve NF, Sun Z, Wong PK and Zhang DD: Dual roles of Nrf2 in cancer. Pharmacol Res 58: 262-270, 2008.

19. Kubben N, Zhang W, Wang L, Voss TC, Yang J, Qu J, Liu GH and Misteli T: Repression of the antioxidant Nrf2 pathway in premature aging. Cell 165: 1361-1374, 2016.

20. Zhou L, Zhang H, Davies KJA and Forman HJ: Aging-related decline in the induction of Nrf2-regulated antioxidant genes in human bronchial epithelial cells. Redox Biol 14: 35-40, 2018.

21. Shibata T, Ohta T, Tong KI, Kokubu A, Odogawa R, Tsuta K, Asamura H, Yamamoto $\mathrm{M}$ and Hirohashi S: Cancer related mutations in Nrf2 impair its recognition by Keap1-Cul3 E3 ligase and promote malignancy. Proc Natl Acad Sci USA 105: 13568-13573, 2008.

22. Kim KY, Park KI, Kim SH, Yu SN, Park SG, Kim YW, Seo YK, Ma JY and Ahn SC: Inhibition of autophagy promotes salinomycin-induced apoptosis via reactive oxygen species-mediated $\mathrm{PI} 3 \mathrm{~K} / \mathrm{AKT} / \mathrm{mTOR}$ and ERK/p38 MAPK-dependent signaling in human prostate cancer cells. Int J Mol Sci 18: 1088, 2017.

23. Xiong Y, Wang Y, Zhang J, Zhao N, Zhang H, Zhang A, Zhao D, Yu Z, Yin Y, Song L, et al: hPMSCs protects against D-galactose-induced oxidative damage of $\mathrm{CD}^{+} \mathrm{T}$ cells through activating Akt-mediated Nrf2 antioxidant signaling. Stem Cell Res Ther 11: 468, 2020.

24. Wang Y, Xiong Y,Zhang A, Zhao N, Zhang J,Zhao D, Yu Z, Xu N Yin Y, Luan X, et al: Oligosaccharide attenuates aging-related liver dysfunction by activating Nrf2 antioxidant signaling. Food Sci Nutr 8: 3872-3881, 2020.

25. Xiong Y, Xiong Y, Zhou S, Yu Z, Zhao D, Wang Z, Li Y, Yan J, Cai Y and Zhang W: Inhibition of glutathione synthesis induced by exhaustive running exercise via the decreased influx rate of L-cysteine in rat erythrocytes. Cell Physiol Biochem 40: 1410-1421, 2016.26.

26. Stasiolek M, Adamczewski Z, Sliwka PW, Puła B, Karwowski B, Merecz-Sadowska A, Dedecjus M and Lewiński A: The molecular effect of diagnostic absorbed doses from ${ }^{131} \mathrm{I}$ on papillary thyroid cancer cells in vitro. Molecules 22: 993, 2017.

27. Xiong Y, Xiong Y, Zhou S, Sun Y, Zhao Y, Ren X, Zhang Y and Zhang N: Vitamin $C$ and E supplements enhance the antioxidant capacity of erythrocytes obtained from aged rats. Rejuvenation Res 20: 85-92, 2017.

28. Rotruck JT, Pope AL, Ganther HE, Swanson AB, Hafeman DG and Hoekstra WG: Selenium: Biochemical role as a component of glutathione peroxidase. Science 179: 588-590, 1973

29. Góth L: A simple method for determination of serum catalase activity and revision of reference range. Clin Chim Acta 196: 143-151, 1991.

30. Sun Y, Oberley LW and Li Y: A simple method for clinical assay of superoxide dismutase. Clin Chem 34: 497-500, 1988.

31. Livak KJ and Schmittgen TD: Analysis of relative gene expression data using real-time quantitative PCR and the 2(-Delta Delta C(T)) Method. Methods 25: 402-408, 2001.

32. Dewangan J, Srivastava S and Rath SK: Salinomycin: A new paradigm in cancer therapy. Tumour Biol 39: 1010428317695035, 2017.

33. Hail N Jr and Lotan R: Cancer chemoprevention and mitochondria: Targeting apoptosis in transformed cells via the disruption of mitochondrial bioenergetics/redox state. Mol Nutr Food Res 53: 49-67, 2009.

34. Yadav RK, Chae SW, Kim HR and Chae HJ: Endoplasmic reticulum stress and cancer. J Cancer Prev 19: 75-88, 2014.

35. Lin Y, Jiang M, Chen W, Zhao T and Wei Y: Cancer and ER stress: Mutual crosstalk between autophagy, oxidative stress and inflammatory response. Biomed Pharmacother 118: 109249, 2019. 
36. Li W, Yang J, Luo L, Jiang M, Qin B, Yin H, Zhu C, Yuan X, Zhang J, Luo Z, et al: Targeting photodynamic and photothermal therapy to the endoplasmic reticulum enhances immunogenic cancer cell death. Nat Commun 10: 3349, 2019.

37. Jeong S, Kim DY, Kang SH, Yun HK, Kim JL, Kim BR, Park SH, Na YJ, Jo MJ, Jeong YA, et al: Docosahexaenoic acid enhances oxaliplatin-induced autophagic cell death via the ER stress/Sesn2 pathway in colorectal cancer. Cancers (Basel) 11: 982, 2019.

38. Peñaranda Fajardo NM, Meijer C and Kruyt FA: The endoplasmic reticulum stress/unfolded protein response in gliomagenesis, tumor progression and as a therapeutic target in glioblastoma. Biochem Pharmacol 118: 1-8, 2016.

39. Shen Y, Yang J, Zhao J, Xiao C, Xu C and Xiang Y: The switch from ER stress-induced apoptosis to autophagy via ROS-mediated JNK/p62 signals: A survival mechanism in methotrexate-resistant choriocarcinoma cells. Exp Cell Res 334: 207-218, 2015

40. Xian M, Cao H, Cao J, Shao X, Zhu D, Zhang N, Huang P, Li W, Yang B, Ying M, et al: Bortezomib sensitizes human osteosarcoma cells to adriamycin-induced apoptosis through ROS-dependent activation of p-eIF2 $\alpha / \mathrm{ATF} 4 / \mathrm{CHOP}$ axis. Int J Cancer 141: 1029-1041, 2017.

41. Wardyn JD, Ponsford AH and Sanderson CM: Dissecting molecular cross-talk between $\mathrm{Nrf} 2$ and $\mathrm{NF}-\kappa \mathrm{B}$ response pathways. Biochem Soc Trans 43: 621-626, 2015.
42. Wang Y, Xiong Y, Zhang A, Zhao N, Zhang J, Zhao D, Yu Z, Xu N, Yin Y, Luan X, et al: Oligosaccharide attenuates aging-related liver dysfunction by activating Nrf2 antioxidant signaling. Food Sci Nutr 8: 3872-3881, 2020.

43. Towers CG, Fitzwalter BE, Regan D, Goodspeed A, Morgan MJ, Liu CW, Gustafson DL and Thorburn A: Cancer cells upregulate Nrf2 signaling to adapt to autophagy inhibition. Dev Cell 50: 690-703.e6, 2019.

44. Rodrigues C, Milkovic L, Bujak IT, Tomljanovic M, Soveral G and Cipak Gasparovic A: Lipid profile and aquaporin expression under oxidative stress in breast cancer cells of different malignancies. Oxid Med Cell Longev 2019: 2061830, 2019.

45. Zhang XQ, Yao C, Bian WH, Chen X, Xue JX, Zhu ZY, Ying Y, $\mathrm{Xu}$ YL and Wang C: Effects of Astragaloside IV on treatment of breast cancer cells execute possibly through regulation of Nrf2 via PI3K/AKT/mTOR signaling pathway. Food Sci Nutr 7: 3403-3413, 2019.

cc)(요 This work is licensed under a Creative Commons Attribution-NonCommercial-NoDerivatives 4.0 International (CC BY-NC-ND 4.0) License. 